In Building the European Capacity in Operational Oceanography, Proceedings of the Third International Conference on EuroGOOS Athens, Greece 3-6 December 2002. Elsevier Oceanography Series. Volume 69. pp. 645-648

2003

Eds H. Dahlin, N.C. Flemming, K. Nittis and S.E. Petersson

ISBN 9780444515506

http://dx.doi.org/10.1016/S0422-9894(03)80107-1

http://archimer.ifremer.fr/doc/00351/46177/

(c) 2013 Elsevier B.V. All rights reserved.

\title{
MEDAR/MEDATLAS 2002: A Mediterranean and Black Sea database for operational oceanography Elsevier Oceanography Series
}

Fichaut Michele ${ }^{1}$, Garcia Maria-Jesus ${ }^{2}$, Giorgetti Alessandra ${ }^{3}$, lona Athanasia ${ }^{4}$, Kuznetsov Alexander
${ }^{\text {, Rixen Michel }}{ }^{6}$, Medar Group

\begin{abstract}
:
A comprehensive database of temperature, salinity and bio-chemical parameters in the Mediterranean and Black Sea has been constructed through comprehensive co-operation between the bordering countries. Statistical climatologies have been computed with all assembled and quality controlled data. The database, designed to initiate and validate prediction models, also represents a system to qualitycheck new incoming data produced by ocean observing systems.
\end{abstract}

Keywords : Database, temperature, salinity, nutrients, climatology, quality control 
Access to basic oceanographic parameters like temperature, salinity and nutrients is a prerequisite for the operational oceanography, for model initialisation and validation as well as to perform quality checks of the new data collected. However these data are in general not easily accessible as they are dispersed among all the different organizations which carry out oceanographic cruises, presently about 150 laboratories from 33 countries. Downhill, it is important that the data collected in real time and delayed mode from the operational oceanography can be integrated in long time series of data of the same type. It was the overall objective of the EU concerted action MEDAR/MEDATLAS (MAS3-CT98-0174 \& ERBIC20-CT98-0103) to answer these questions, with in short term, to make available a comprehensive data product of such multi-disciplinary in-situ data and information in the Mediterranean and Black Sea, through a wide co-operation of the Mediterranean and Black Sea countries.

Accordingly the specific project objectives were: 1. to compile and safeguard historical data; 2 . to make available comparable and compatible data sets of : temperature, salinity, oxygen, nitrate, nitrite, ammonia, total nitrogen, phosphate, total phosphorus, silicate, H2S, $\mathrm{pH}$, alkalinity, chlorophyll-a profiles by using a common protocol for formatting and quality checking; 3 . to prepare and disseminate qualified value added products by using efficient gridding and mapping methodology; 4 . to enhance communication between data managers and scientists to improve the data circulation.

Each participant, who represents the National Co-ordinator for International Oceanographic Data and Information Exchange (IODE) at the Intergovernmental Oceanographic Commission (IOC) of UNESCO, have compiled and safeguarded copies of the data sets dispersed in the scientific laboratories of his country, and reformat them at the common MEDATLAS format. These data sets has been checked for quality (QC) according to the common protocol based on the international IOC, ICES and EC/MAST recommendations, with automatic (objective) and visual (subjective) checks.

The data management structure was distributed between four Regional Data Centres (RDC) and one co-ordinating and Global Assembling Centre (GAC). Each National Oceanographic Data Centre (NODC) or Designated National Agencies (DNA) of the participating countries sent his data set to the corresponding RDC for regional expertise. The data have been gathered and checked for quality in the RDC, and then sent to the GAC which finalise the last quality and duplicate checks. Finally a selection of all the "Good" data interpolated to pre-defined standard levels has been sent to the Analysis Centre (AC) for climatologies computation.

Thanks to this strong international cooperation the volume of available data represents now 286426 stations (vertical profiles). The data released which double the volume of the previously available data, consist of the following number of profiles:

\begin{tabular}{|l|r|}
\hline \multicolumn{1}{|c|}{ DATA TYPE } & NB of STATIONS \\
\hline BOTTLE & 88453 \\
\hline CTD & 36054 \\
\hline MBT & 81465 \\
\hline XBT & 80425 \\
\hline Thermistor string & 29 \\
\hline Total & $\mathbf{2 8 6 4 2 6}$ \\
\hline
\end{tabular}

\begin{tabular}{|l|r|}
\hline \multicolumn{1}{|c|}{ PARAMETER NAME } & NB OF PROFILES \\
\hline SEA TEMPERATURE & 284946 \\
\hline PRACTICAL SALINITY & 118509 \\
\hline DISSOLVED OXYGEN & 44989 \\
\hline NITRATE (NO3-N) & 10588 \\
\hline NITRITE (NO2-N) & 10561 \\
\hline AMMONIUM & 5301 \\
\hline SILICATE & 15936 \\
\hline PHOSPHATE & 20808 \\
\hline ALKALINITY & 2548 \\
\hline PH & 14548 \\
\hline CHLOROPHYLL-A TOTAL & 4716 \\
\hline HYDROGEN SULPHIDE (H2S) & 1843 \\
\hline TOTAL NITROGEN & 153 \\
\hline TOTAL PHOSPORUS & 2381 \\
\hline
\end{tabular}

These data have been objectively analysed to produce gridded climatological fields by up to data variational methods. When the data coverage was sufficient, seasonal and monthly fields have been computed and maps of horizontal and vertical distributions drawn. 
The in-situ and climatological data, the climatological maps and all the documentation about the project are in publication on a set of 4 CDRoms. The in-situ data are accessible through a software designed as a user-friendly interface so that users can extract data from the whole data set, following several criteria.

This software, available for PCMINDOWS, allows:

- $\quad$ extraction and display of any subset of data selected according to any combination of the following criteria: geographical location, data type (bottle, CTD, bathythermograph), cruise name and reference, time period, month, ship, country, parameter, quality flags

- $\quad$ extraction at three output formats: MEDATLAS, Comma Separated Values for spreadsheet, Ocean Data View (WOCE/Bremerhaven University visualisation software)

- interpolation at pre-defined standard levels or at user defined standard levels

- visualisation of the selected data on parameter/ parameter plots

In addition to the data product that give an easy access to the integrated data set of qualified observed and objectively analysed data, two by products are of interest for the operational oceanography. The first is related to the data availability. It can been shown that the data coverage still remain poor in the SE part of the Mediterranean, and also in the middle of the deep basins, especially for the nutrients, but also for parameters like salinity and several months of the year for the temperature. These regions should be covered in priority when designing the operational system. Secondly, the protocols developed for formatting and checking the delayed mode data, are also used to process real time data. An important effort is made now on the protocol for $Q C$ of the nutrients by improving the statistics, adding some further checks like Redfield ration and feedback from the climatological computations. This protocol should be stabilised when the "operational" sensors will be ready to monitor the region.

Finally MEDAR/MEDATLAS is not only a data product on CDrom, but also a living infrastructure for data management based on a network of national data centres, which continuously archive and disseminate data, in real time and delayed mode. This infrastructure is one of the most advanced in the world for data exchange and dissemination. It already successfully contributed to the data management of the operational project "Mediterranean Forecasting Pilot Project". It offers a robust institutional perennial system for data safeguarding. By close collaboration with scientists in charge of data collection and modellisation, it intends also to have an efficient answer to the fast evolving data needs. 